\title{
INVESTIGACIONES
}

\section{Patrimonio, competencias históricas y metodologías activas de aprendizaje. Un análisis de las opiniones de los docentes en formación en España e Inglaterra}

\author{
Heritage, historical competences and active learning methodologies. \\ An analysis of the opinions of teachers in training in Spain and England
}

\author{
Pedro Miralles M., ${ }^{a}$ Cosme Gómez C., ${ }^{a b}$ Raimundo Rodríguez P. ${ }^{a c}$ \\ ${ }^{a}$ Universidad de Murcia \\ Telf.: (34) 868887076. Correo electrónico: pedromir@um.es \\ bTelf.: (34) 868887072. Correo electrónico: cjgomez@um.es
}

'Telf.: (34) 868887077. Correo electrónico: raimundorodriguez@um.es

\begin{abstract}
El objetivo de este trabajo es analizar las percepciones de los docentes de Educación Secundaria en formación sobre el patrimonio y su rol en la enseñanza y el aprendizaje de la historia. Se ha seleccionado la información de esta temática del cuestionario titulado "Opinión y percepción del profesorado en formación inicial sobre el aprendizaje de la historia y la evaluación de competencias históricas”. La muestra la componen 506 estudiantes del Máster de Formación del Profesorado de Educación Secundaria en España (344) y del Postgraduate Certificate in Education (PGCE) y el Teach First en Inglaterra (162). Participaron 22 universidades: 13 españolas y 9 inglesas. Los datos han sido codificados en el programa estadístico SPSS v21.0, y se ha realizado un análisis descriptivo, tablas de contingencia, pruebas estadísticas y correlaciones. Los resultados muestran una estrecha vinculación entre la valoración positiva del patrimonio, el uso de metodologías activas de aprendizaje y una concepción epistemológica de la historia como saber crítico.
\end{abstract}

Palabras clave: patrimonio, enseñanza de la historia, formación docente.

\begin{abstract}
The objective of this work is to analyze the perceptions of the teachers of Secondary Education in formation on the heritage and its role in the teaching and learning of History. The information on this subject has been selected of the questionnaire entitled "Opinion and perception of teachers in initial formation on the learning of history and the evaluation of historical competences". The sample consists of 506 students of the Master's Training Teacher of Secondary Education in Spain (344) and the Postgraduate Certificate in Education (PGCE) and Teach First in England (162). 22 universities participated: 13 Spanish and 9 English. The data were coded in the statistical program SPSS v21.0, and descriptive analysis, contingency tables, statistical tests and correlations were carried out. The results show a close link between the positive valuation of heritage, the use of active learning methodologies and an epistemological conception of history as critical knowledge.
\end{abstract}

Keywords: heritage, history teaching, teacher training. 
Estudios Pedagógicos XLIII, N 4: 161-184, 2017

PATRIMONIO, COMPETENCIAS HISTÓRICAS Y METODOLOGÍAS ACTIVAS DE APRENDIZAJE. UN ANÁLISIS DE LAS OPINIONES DE LOS DOCENTES EN FORMACIÓN EN ESPAÑA E INGLATERRA

\section{INTRODUCCIÓN. PATRIMONIO, PENSAMIENTO HISTÓRICO Y METODOLOGÍAS ACTIVAS DE APRENDIZAJE}

En la última década se han multiplicado los trabajos que han profundizado en los vínculos y reciprocidades entre la educación patrimonial, la educación histórica, la construcción de una ciudadanía crítica y una educación identitaria no excluyente. Estudios en el ámbito internacional como los de Copeland (2009), Davis (2007), Gosselin y Livingstone (2016), Pinto (2013), Semedo (2015) o Van Boxtel, Grever y Klein (2015) son ejemplos de ese esfuerzo de integración. Pero también en España, donde existen muchos grupos de investigación consolidados que están analizando las conexiones entre educación formal y no formal con respecto al patrimonio, la identidad y educación para la formación de ciudadanos. Trabajos como los de Calaf (2010), Cuenca (2002), Estepa (2013), Fontal (2003), Fontal y Gómez-Redondo (2016), Fontal e Ibáñez (2015), Martín y Cuenca, (2011) o Vicent, Ibáñez y Asensio (2015) establecen una visión del patrimonio y de la educación patrimonial de carácter sistémico, participativo, interactivo, complejo y sociocrítico (Cuenca, Molina \& Martín, 2017).

El reciente monográfico en la prestigiosa Revista de Educación dirigido por Olaia Fontal y Álex Ibáñez muestra la fuerza de esta línea de investigación en nuestro país. Cabe destacar entre ellos el estudio de Cuenca, Estepa y Martín (2017) sobre la relación entre el patrimonio, la ciudadanía y la construcción de la identidad; y el trabajo de Fontal e Ibáñez (2017), en el que realizan un riguroso estudio bibliométrico de la producción científica sobre educación patrimonial. En todo caso, hay que destacar la cantidad y calidad de trabajos sobre investigación y experiencias de innovación desde la educación patrimonial, y que tienen sus ejes en Barcelona, Huelva, País Vasco, Valladolid, Murcia y Zaragoza (Cuenca \& López, 2014; Cuenca, Martín \& Estepa, 2011; Feliu \& Hernández, 2015; Fontal, 2006; González \& Feliu, 2015; Ibáñez, 2006; Ibáñez, Gillate \& Madariaga, 2015; Ibáñez, Vicent \& Asensio, 2012; Ibáñez et al., 2014; Molina, Escribano \& Díaz, 2016; Monteagudo, 2014; Monteagudo \& Miralles, 2014; Monteagudo, Miralles \& Martínez, 2009; Rivero \& Hernández, 2015; Santacana \& Llonch, 2012, 2016; Santacana \& Martínez, 2013; Santacana \& Masriera, 2012; Vicent, Rivero \& Feliu, 2015). También son muy interesantes las propuestas que provienen del grupo de investigación RODA, de la Universidad de Santiago de Compostela, que unen elementos patrimoniales, el conflicto identitario y las habilidades del historiador para la argumentación histórica (Domínguez \& López, 2015, 2017).

Afortunadamente, cada vez son más frecuentes y ricas las experiencias en el aula con objetos y restos materiales del pasado. De hecho, Philips (2011) hace una valoración muy positiva de los artículos publicados sobre esta cuestión en la revista Teaching History desde la década de 1990, haciendo hincapié en los cambios metodológicos que se han producido gracias a la incorporación de estas propuestas de trabajo. Trabajos como los de Bardavio y González (2003), Corbishley (2011), Larouche (2016), Levstik, Henderson y Schlarb (2008) o Santacana y Masriera (2012) insisten en los aspectos positivos de estas experiencias.

Los vínculos entre el uso del patrimonio para el desarrollo del pensamiento histórico son evidentes. El proyecto canadiense Benchmarks of Historical Thinking identificó seis conceptos de pensamiento histórico (Seixas \& Morton, 2013): relevancia histórica, fuentes y pruebas históricas, causas y consecuencias, cambios y permanencias, perspectiva histórica y dimensión ética de la historia. Aunque el patrimonio puede utilizarse en el aula y fuera de ella para el desarrollo de cualquiera de estos conceptos, sin duda tiene su base en el 
concepto de fuentes y pruebas históricas, entendido como el análisis crítico e interpretación de fuentes, la capacidad para extraer pruebas de las mismas y que permitan construir un argumento histórico propio. Estos conceptos de segundo orden han estado en el centro de un debate internacional en torno al aprendizaje de la historia basado en las habilidades del historiador (Gómez \& Miralles, 2015; Gómez, Ortuño \& Molina, 2014; Lévesque, 2011; Prats \& Santacana, 2011; Sáiz, 2013, 2015; VanSledright, 2014; Wineburg, 2001). Este enfoque se centra en comprender la historia como un método, aprender a pensar y reflexionar con y desde la historia.

El concepto del pensamiento histórico no es nuevo, de hecho, ya se mencionó a finales del siglo XIX en Estados Unidos en el marco de la Asociación Histórica Americana (Lévesque, 2011). No obstante, ha adquirido mayor fuerza durante las dos últimas décadas como una postura alternativa al discurso histórico descriptivo y acrítico. Éthier, Demers y Lefrançois (2010), tras una revisión de la bibliografía publicada en francés, inciden en el carácter metódico del pensamiento histórico. Estos autores insisten en que este concepto hace referencia a la capacidad para construir el conocimiento del pasado, y que integra tanto la perspectiva temporal como una interpretación crítica. Las fuentes y el método del historiador, por tanto, forman una parte consustancial de esta definición del pensamiento histórico, si bien los resultados no dejan de mostrar las grandes dificultades de los alumnos para la generación de interpretaciones que aúnen fuentes con información divergente (Sánchez Agustí, 2011).

El concepto de fuente material como recurso didáctico para la enseñanza de la historia puede definirse como una combinación de objetos y vestigios del pasado con soporte físico (Prats \& Santacana, 2011), aunque actualmente se está incorporando el patrimonio cultural e inmaterial como una fuente importante para el conocimiento y reflexión del pasado (Santacana \& Llonch, 2016). Ashby (2011) señaló varias cuestiones necesarias para comprender el trabajo con fuentes en el aula. En primer lugar, la fuente histórica es un concepto, no una habilidad o una competencia. En segundo lugar, es necesario distinguir entre fuentes y pruebas históricas. Mientras que el concepto de fuente histórica se refiere a todos los vestigios materiales e inmateriales que nos han llegado del pasado, el concepto de prueba histórica hace referencia a la obtención explícita de información (Domínguez, 2015).

No cabe duda de que el trabajo con objetos, artefactos y otras fuentes primarias es imprescindible para el desarrollo de la interpretación histórica. En realidad, el origen de estas propuestas educativas proviene de los cambios pedagógicos llevados a cabo en Europa y EE. UU. por la Escuela Nueva a finales del siglo XIX y comienzos del siglo XX, y que en España tuvo su máximo representante en Giner de los Ríos y la Institución de Libre Enseñanza, en general, y en Rafael Altamira en el caso de la enseñanza de la historia. En sus propuestas progresistas, basadas en un aprendizaje activo, participativo, centrado en los intereses del niño y en una enseñanza dinámica, ya apuntaban la necesidad de introducir los restos materiales, objetos y artefactos producidos por las diferentes sociedades a lo largo del tiempo (Santacana \& Llonch, 2012). Las propuestas didácticas de Altamira (1891/1997) siguen totalmente vigentes: utilizar lecturas históricas escogidas, narraciones de hechos concretos, biografías de personajes; despertar el interés del niño y motivar su participación mediante el juego adecuado a su realidad; emplear y crear láminas, proyecciones, ilustraciones y decorados que completen el juego; aprovechar la actualidad (noticias de prensa, efemérides, conmemoraciones), todo lo que interesa a la comunidad; llevar a cabo una enseñanza activa por medio de los museos y las salidas a lugares cercanos, excursiones o paseos históricos; 
usar el libro de texto como un complemento aclaratorio, ya que no es eficaz en Educación Primaria, debe hacer funciones de epítome inicial o final, resumen o síntesis explicativa; valerse de las explicaciones orales con el apoyo primordial de materiales, que deben ser la base e irán especializándose conforme se utilice el libro con más asiduidad; desarrollar una educación en valores: la historia contribuye a la formación ética y moral.

Este proceso que une los elementos patrimoniales con el fomento del pensamiento histórico requiere de un cambio en la metodología del docente en el aula, pasar de la lección magistral a la utilización de métodos de indagación, métodos activos de aprendizaje y el uso de una variedad de recursos (Gómez \& Rodríguez, 2014). En el apartado metodológico, el aprendizaje basado en problemas resulta muy útil frente a los planteamientos tradicionales expositivos (Oller, 2011). A través del trabajo basado en la resolución de problemas es posible establecer discursos sintéticos que faciliten ordenar y estructurar la información histórica. La simulación o el debate sobre situaciones reales permiten establecer esa relación sistémica de los conocimientos históricos, al tiempo que movilizan actitudes y modos de operar. De igual forma, los estudios de caso (Gil \& Ibáñez, 2013; Prats, 2005) y la incorporación del estudio de la realidad y los fenómenos sociales (Miralles \& Molina, 2011) muestran una innovadora forma de acercar los conocimientos históricos al alumnado. Además, permiten una mayor aplicación de estos contenidos en la comprensión y el análisis de la sociedad y que los estudiantes los conciban más allá de saberes cerrados y poco prácticos. Los docentes deberán fomentar los debates, las puestas en común, las discusiones y estudios para que el alumnado conozca y participe en la comunidad escolar a la que pertenece (Tarr, 2016). El estudio de un acontecimiento histórico es la ocasión perfecta para reforzar en el alumnado tanto capacidades y actitudes como para desarrollar el dominio de técnicas e instrumentos.

El método de proyectos o aprendizaje basado en proyectos intenta desarrollar un aprendizaje basado en la realidad y aplicar las propuestas de pedagogos como Dewey, que querían aplicar en las aulas técnicas de indagación y convertirlas en "escuela-laboratorio" (Domínguez, 2004). El papel activo del estudiante en el proceso de construcción del conocimiento histórico es uno de los principales elementos claves del método de proyectos (Del Moral \& Sobrino, 2016). Como indican los anteriores autores, el docente es un gestor de espacios y de situaciones de aprendizaje. Propuestas concretas para la enseñanza de la historia como las desarrolladas por De la Calle (2016), Marín (2016) o Redondo (2016) muestran la potencialidad didáctica de esta metodología.

Para mejorar la educación histórica es necesario que los docentes apuesten por metodologías alternativas. Pero también que cambien los lastres epistemológicos que conciben la historia como un conjunto de conocimientos cerrados y apuesten por el desarrollo de un pensamiento histórico a través de recursos claves como el patrimonio. Indagar en la formación de quienes en el futuro serán docentes puede darnos una perspectiva de lo que debe modificarse.

\section{MÉTODO}

\subsection{OBJETIVOS}

El objetivo principal de este trabajo es realizar un estudio comparativo de la valoración y las concepciones de los docentes en formación de España e Inglaterra, sobre el papel del 
patrimonio para la enseñanza de la historia y el desarrollo y la evaluación de competencias históricas. Para conseguir este objetivo se han planteado tres objetivos específicos:

- Comparar la valoración que tienen los docentes en formación de España e Inglaterra sobre el patrimonio y su papel en el proceso de enseñanza-aprendizaje de la historia.

- Diferenciar la estimación que realizan los docentes en formación de España e Inglaterra sobre el papel del patrimonio en el desarrollo y la evaluación de competencias históricas.

- Analizar las correlaciones entre los ítems del cuestionario para interpretar las diferentes formas de concebir el patrimonio en la clase de Historia y en la evaluación de competencias históricas por parte de los docentes en formación de España e Inglaterra.

\subsection{PARTICIPANTES}

Se han recogido 506 cuestionarios de estudiantes del Máster de Formación del Profesorado de Educación Secundaria en la especialidad de Geografía e Historia en España (344) y del Postgraduate Certificate in Education (PGCE) y el Teach First en Inglaterra (162) ${ }^{1}$. En la investigación participaron 22 universidades, 13 españolas y 9 inglesas. Se ha procurado tener una amplia representación territorial. En el caso español hay representantes de universidades del norte peninsular (Santander y Oviedo), del centro (Burgos, Valladolid, La Rioja, Zaragoza y Madrid), del Levante (Murcia, Alicante, Valencia y Barcelona) y del sur (Málaga y Jaén). Además, la muestra la compone una combinación de universidades grandes, medianas y pequeñas. En cuanto a la muestra de Inglaterra, la amplitud territorial también ha sido muy representativa: participaron universidades del norte (Manchester, York, Leeds y Edge Hill), del centro (East-Anglia y Birmingham), suroeste (Exeter), de la capital (IoE-UCL) y del sureste (Canterbury). Igual que en el caso español, también hay una combinación de universidades grandes, medianas y pequeñas.

Teniendo en cuenta que en España hay 39 universidades públicas que ofertan el Máster de Formación del Profesorado en la especialidad de Geografía e Historia, y con una estimación de 1170 alumnos (30 matriculados por universidad), con los datos obtenidos (344 cuestionarios) tendríamos un nivel de confianza del 97\% y un 5\% de error máximo de estimación. No tenemos datos oficiales de las universidades inglesas. Según los datos proporcionados por un experto inglés del área consultado, el alumnado matriculado en PGCE y Teach First en Inglaterra para la formación como profesor de Historia en Secundaria estaría en torno a 700-800. Si aceptamos esas cifras como válidas, con los datos obtenidos de los cuestionarios ingleses tenemos un nivel de confianza del $95 \%$ y un $7 \%$ de error máximo de estimación. Los datos demográficos de la muestra están presentes en las tablas 1,2 y 3 .

Queremos agradecer al profesor Arthur Chapman la ayuda prestada en la recogida de información del cuestionario en Inglaterra, ya que nos ayudó a ponernos en contacto con todas las universidades inglesas de las que se ha recogido información. 
Estudios Pedagógicos XLIII, N 4: 161-184, 2017

PATRIMONIO, COMPETENCIAS HISTÓRICAS Y METODOLOGÍAS ACTIVAS DE APRENDIZAJE. UN ANÁLISIS DE LAS OPINIONES DE LOS DOCENTES EN FORMACIÓN EN ESPAÑA E INGLATERRA

Tabla 1. Participantes que respondieron al cuestionario en España e Inglaterra

\begin{tabular}{|l|c|c|}
\hline & Frecuencia & Porcentaje \\
\hline España & 344 & 67,9 \\
\hline Inglaterra & 162 & 32,1 \\
\hline Total & 506 & 100 \\
\hline
\end{tabular}

Tabla 2. Edad de los participantes que respondieron al cuestionario en España e Inglaterra

\begin{tabular}{|l|l|c|c|c|c|}
\hline \multicolumn{2}{|c|}{} & $\begin{array}{c}\text { Frecuencia } \\
\text { España }\end{array}$ & $\begin{array}{c}\text { Porcentaje } \\
\text { España }\end{array}$ & $\begin{array}{c}\text { Frecuencia } \\
\text { Inglaterra }\end{array}$ & $\begin{array}{c}\text { Porcentaje } \\
\text { Inglaterra }\end{array}$ \\
\hline \multirow{6}{*}{ NTota } & $20-25$ & 214 & 62,2 & 98 & 60,5 \\
\cline { 2 - 6 } & $26-30$ & 68 & 19,8 & 33 & 20,4 \\
\cline { 2 - 6 } & $31-35$ & 18 & 5,2 & 3 & 1,9 \\
\cline { 2 - 6 } & $36-40$ & 12 & 3,5 & 6 & 3,7 \\
\cline { 2 - 6 } & $41-45$ & 3 & 0,9 & 4 & 2,5 \\
\cline { 2 - 6 } & $46-50$ & 0 & 0 & 1 & 0,6 \\
\cline { 2 - 6 } & $51-55$ & 0 & 0 & 0 & 0,0 \\
\cline { 2 - 6 } & $56-60$ & 0 & 0 & 0 & 0,0 \\
\cline { 2 - 6 } & + de 60 & 1 & 0,3 & 0 & 0,0 \\
\cline { 2 - 6 } & NC & 28 & 8,1 & 17 & 10,5 \\
\cline { 2 - 6 } & Total & 344 & 100 & 162 & 60,5 \\
\hline
\end{tabular}

Tabla 3. Género de los participantes en el cuestionario en España e Inglaterra

\begin{tabular}{|l|l|c|c|c|c|}
\hline \multicolumn{2}{|c|}{} & $\begin{array}{c}\text { Frecuencia } \\
\text { España }\end{array}$ & $\begin{array}{c}\text { Porcentaje } \\
\text { España }\end{array}$ & $\begin{array}{c}\text { Frecuencia } \\
\text { Inglaterra }\end{array}$ & $\begin{array}{c}\text { Porcentaje } \\
\text { Inglaterra }\end{array}$ \\
\hline \multirow{2}{*}{} & Hombre & 187 & 54,4 & 61 & 37,7 \\
\cline { 2 - 6 } & Mujer & 139 & 40,4 & 100 & 61,7 \\
\cline { 2 - 6 } & Total & 326 & 94,8 & 161 & 99,4 \\
\hline Perdidos & Sistema & 18 & 5,2 & 1 &, 6 \\
\hline Total & 344 & 100,0 & 162 & 100 \\
\hline
\end{tabular}




\subsection{DISEÑO DE LA INVESTIGACIÓN}

El diseño empleado en la presente investigación ha sido un diseño cuantitativo no experimental tipo encuesta. Se ha optado por este tipo de diseño debido a que se trata de un método de investigación capaz de dar respuesta a problemas tanto en términos descriptivos como de relación de variables cuando la información es recogida de forma sistemática, garantizando el rigor de los datos obtenidos (Buendía, Colás \& Hernández, 1998; Hernández \& Maquilón, 2010).

\subsection{INSTRUMENTO DE RECOGIDA DE INFORMACIÓN}

Los datos utilizados para este trabajo forman parte de un cuestionario con una escala de valoración cerrada tipo Likert (1-5). El título del cuestionario ha sido "Opinión y percepción del profesorado en formación inicial sobre el aprendizaje de la historia y la evaluación de competencias históricas". El cuestionario fue validado por cuatro expertos, tres de ellos del área de Didáctica de las Ciencias Sociales de tres universidades distintas, y con amplia experiencia en Educación Secundaria. El cuarto validador es profesor del área de Métodos de Investigación y Diagnóstico en Educación. Los expertos validadores completaron un cuestionario con una escala Likert de 1-4. Se dejaron solamente los ítems que superaran el 3 de media por los validadores. Además se modificaron todas las cuestiones señaladas de forma cualitativa.

El cuestionario tiene dos partes: la primera parte es de identificación y la segunda parte está formada por tres bloques temáticos con los ítems que deben valorar los participantes. El primer bloque, titulado "Opinión y percepción sobre la evaluación y su papel en el proceso de enseñanza y aprendizaje", contiene 12 afirmaciones sobre el papel de la evaluación que los participantes debían valorar desde 1 (totalmente en desacuerdo) hasta 5 (totalmente de acuerdo). El segundo bloque, titulado "Opinión y percepción sobre la historia como materia formativa, métodos, fuentes y recursos de enseñanza”, contiene 15 afirmaciones que los participantes deben valorar desde 1 (totalmente en desacuerdo) hasta 5 (totalmente de acuerdo), y 24 métodos, técnicas y recursos didácticos para la enseñanza de la historia que los participantes deben valorar desde 1 (menos relevante) hasta 5 (más relevante). El tercer bloque, titulado "Opinión y percepción sobre la evaluación de competencias históricas en Educación Secundaria: utilización de fuentes, razonamiento causal y empatía histórica", contiene 9 afirmaciones que los participantes deben valorar desde 1 (totalmente en desacuerdo) hasta 5 (totalmente de acuerdo), y 8 actividades de evaluación de competencias históricas que los participantes deben valorar desde 1 (menos relevante) hasta 5 (más relevante). Los ítems del cuestionario relacionados con los procedimientos y las actividades de evaluación se han construido teniendo en cuenta las prácticas docentes relacionadas con perfiles tradicionales e innovadores (Gómez, Miralles \& Chapman, 2017).

Tras realizar la validación del cuestionario por los expertos, este fue traducido al inglés y se sometió a la validación del comité de ética del Institute of Education (University College of London) para poder aplicarlo en centros ingleses. Para ello se rellenó el "Staff Ethics Application Form" con la información sobre los procedimientos y la metodología que se iba a utilizar en la recogida y el análisis de la información. El comité de ética del Institute of Education resolvió positivamente sobre el cuestionario, lo que permitió distribuirlo en centros españoles e ingleses entre mayo y junio. 
Estudios Pedagógicos XLIII, N 4: 161-184, 2017

PATRIMONIO, COMPETENCIAS HISTÓRICAS Y METODOLOGÍAS ACTIVAS DE APRENDIZAJE. UN ANÁLISIS DE LAS OPINIONES DE LOS DOCENTES EN FORMACIÓN EN ESPAÑA E INGLATERRA

Los datos seleccionados para este trabajo corresponden principalmente al conjunto de ítems 2.24 y 2.25 del bloque II "Opinión y percepción sobre la historia como materia formativa, métodos, fuentes y recursos de enseñanza", titulados respectivamente "Valora del 1 (menos relevante) al 5 (más relevante) los materiales y recursos que según su opinión son más adecuados para la enseñanza de la historia en Educación Secundaria", y "Valora del 1 (menos relevante) al 5 (más relevante) los métodos y estrategias que según su opinión son más adecuados para la enseñanza de la historia en Educación Secundaria". También se han analizado los datos del conjunto del ítem 3.35 del bloque 3, titulado "Valora del 1 (menos relevante) al 5 (más relevante) los ejercicios y actividades que según su opinión son más adecuados para evaluar el aprendizaje de los contenidos y las competencias históricas en Educación Secundaria". Con el análisis de estos ítems hemos comprobado el papel que los futuros docentes le dan al patrimonio en los métodos, recursos y ejercicios de evaluación de competencias históricas. Además hemos realizado pruebas estadísticas y correlaciones bivariadas con otros ítems del cuestionario, relacionados con las concepciones epistemológicas de la historia y las percepciones sobre sus posibilidades formativas (Bloque 2, ítems 2.23). En las siguientes tablas se pueden comprobar las afirmaciones y valoraciones utilizadas para el análisis de resultados.

Tabla 4. Ítems del bloque 2 del cuestionario

"Opinión y percepción del profesorado en formación inicial sobre el aprendizaje de la historia y la evaluación de competencias históricas"

13. La historia como disciplina académica se basa sobre todo en el conocimiento de los hechos del pasado.

14. Los relatos históricos se fundamentan en una interpretación subjetiva por parte del historiador.

15. La historia consiste en una investigación crítica del pasado.

16. El desacuerdo entre historiadores sobre un mismo hecho en el pasado siempre se debe a las dificultades de la fuente y a la falta de pruebas y evidencias.

17. Los contenidos históricos propuestos en los currículos educativos en un país deben basarse en los principales acontecimientos relacionados con el origen y consolidación de esa nación.

18. Los métodos del historiador y los contenidos procedimentales deben tener un papel fundamental en los currículos educativos.

19. Las buenas habilidades de lectura, memorización y comprensión por parte del alumnado son suficientes para aprender bien la historia e interpretar las fuentes históricas.

20. Es complicado usar métodos de indagación para la enseñanza de la historia en Educación Secundaria. Los resultados pueden conllevar elementos subjetivos y alejados del objetivo inicial.

21. El uso de las nuevas tecnologías ayuda a mejorar el conocimiento histórico del alumnado, por la mayor interactividad y experiencia visual.

22. Las nuevas tecnologías sólo ayudan a mejorar el conocimiento histórico del alumnado cuando permiten el acceso al trabajo con fuentes primarias. 
Tabla 5. Ítems 2.23 del cuestionario. Valora del 1 (menos relevante) al 5 (más relevante) el papel que en su opinión debe tener la historia como materia formativa en Educación Secundaria

2.23.1. Comprender el presente

2.23.2. Conocer el origen y consolidación de la nación

2.23.3. Educarse en valores sociales y cívicos

2.23.4. Conocer los métodos de reconstrucción y explicación de los hechos históricos

2.23.5. Desarrollar competencias educativas en vocabulario, cronología, etc.

2.23.6. Otros (indica cuál)

Tabla 6. Ítem 2.24 del cuestionario. Valora del 1 (menos relevante) al 5 (más relevante) los materiales y recursos que según su opinión son más adecuados para la enseñanza de la historia en Educación Secundaria

\subsubsection{Libro de texto}

2.24.2. Internet

2.24.3. Fuentes documentales primarias

2.24.4. Fuentes orales (entrevistas a abuelos, familiares, vecinos)

2.24.5. Prensa diaria impresa o digital

2.24.6. Apuntes del profesor

2.24.7. Museos y otros centros de interés histórico y patrimonial

2.24.8. Cine histórico

2.24.9. Documentales de temática histórica

2.24.10. Novela histórica

2.24.11. Revistas de divulgación

2.24.12. Videojuegos

2.24.13. Cómics

2.24.14. Fiestas y tradiciones locales de contenido histórico

2.24.15. Otra (indica cuál) 
Estudios Pedagógicos XLIII, N 4: 161-184, 2017

PATRIMONIO, COMPETENCIAS HISTÓRICAS Y METODOLOGÍAS ACTIVAS DE APRENDIZAJE. UN ANÁLISIS DE LAS OPINIONES DE LOS DOCENTES EN FORMACIÓN EN ESPAÑA E INGLATERRA

Tabla 7. Ítem 2.25 del cuestionario. Valora del 1 (menos relevante) al 5 (más relevante) los métodos y estrategias que según su opinión son más adecuados para la enseñanza de la historia en Educación Secundaria

\begin{tabular}{|l|}
\hline $\begin{array}{l}\text { 2.25.1. Explicación del profesor } \\
\text { 2.25.2. Estrategias de simulación histórica }\end{array}$ \\
\hline $\begin{array}{l}\text { 2.25.3. Utilizar temas claves de interés actual para conectar pasado y presente } \\
\text { ción y tratamiento de la información }\end{array}$ \\
\hline $\begin{array}{l}\text { 2.25.5. Estudios en profundidad de casos históricos concretos, donde el alumnado } \\
\text { deba investigar y después exponer los resultados }\end{array}$ \\
\hline \begin{tabular}{l} 
2.25.6. Salidas a centros de interés histórico del entorno cercano \\
\hline 2.25.7. Debates dirigidos sobre temas históricos
\end{tabular} \\
\hline 2.25.8. Otro (indica cuál) \\
\hline
\end{tabular}

Tabla 8. Ítem 3.35 del cuestionario. Valora del 1 (menos relevante) al 5 (más relevante) los ejercicios y actividades que según su opinión son más adecuados para evaluar el aprendizaje de los contenidos y las competencias históricas en Educación Secundaria

\begin{tabular}{|l|}
\hline 3.35.1. Comentarios de textos e imágenes de contenido histórico \\
\hline \begin{tabular}{l} 
3.35.2. Preguntas cortas sobre acontecimientos históricos \\
\hline 3.35.3. Ensayos y preguntas de desarrollo sobre procesos históricos
\end{tabular} \\
\hline $\begin{array}{c}\text { 3.35.4. Trabajo de campo (recogida de información, realización de ejercicios) a lo } \\
\text { largo de una visita a un museo u otro centro de interés histórico }\end{array}$ \\
\hline $\begin{array}{l}\text { 3.35.5. Ejercicios de empatía histórica } \\
\text { 3.35.6. Investigaciones de historia local }\end{array}$ \\
\hline $\begin{array}{l}\text { 3.35.7. Preguntas que busquen la explicación histórica y el razonamiento causal } \\
\text { 3.35.8. Pruebas objetivas (tipo test, enlazar fechas con acontecimientos) }\end{array}$ \\
\hline
\end{tabular}

Los datos fueron codificados en el programa estadístico SPSS v21.0 en dos archivos distintos: uno para cada realidad territorial y otro con todos los datos en conjunto. Esto nos ha permitido realizar el análisis por separado y también un estudio comparativo. Para este artículo se ha realizado un análisis descriptivo (frecuencias, media y varianza para cada uno de los ítems seleccionados), y correlaciones bivariadas en los ítems que presentan unos resultados descriptivos relevantes. 


\section{ANÁLISIS Y DISCUSIÓN DE RESULTADOS}

\subsection{EL PAPEL DEL PATRIMONIO EN LA CLASE DE HISTORIA}

En la Tabla 9 se muestran los estadísticos descriptivos del bloque 2.24 del cuestionario, en el que los docentes en formación debían valorar diferentes recursos por su adecuación a la enseñanza de la historia en Educación Secundaria. Como se puede comprobar en dicha tabla, el ítem "Museos y otros centros de interés histórico" es el más valorado por los docentes en formación en España, y el segundo más valorado en el caso de los docentes en formación ingleses. En Inglaterra únicamente lo supera la valoración del ítem "Fuentes documentales primarias". En el caso de España, además del ítem de museos, solo supera el 4 de valoración las fuentes documentales primarias, las fuentes orales y documentales de temática histórica. En el caso de Inglaterra solo superan el 4 de valoración el ítem de museos y el de fuentes documentales primarias. Los ítems con menor apreciación en el caso de España son el libro de texto, los cómics y los videojuegos. En el caso inglés, los ítems de menor estimación son los cómics, los videojuegos y la novela histórica. El otro ítem relacionado con el patrimonio, "Fiestas y tradiciones locales de contenido histórico", se queda en una posición intermedia, con 3,52 de valoración en el caso de España y 3,42 en el caso inglés. A pesar de los esfuerzos en los últimos años por dar valor al patrimonio inmaterial en la enseñanza de la historia (Santacana \& Llonch, 2016), todavía los docentes en formación no le dan una apreciación tan importante como al patrimonio material (museos, objetos, sitios arqueológicos, etc.).

Tabla 9. Estadísticos descriptivos de los ítems del bloque 2.24 del cuestionario

\begin{tabular}{|l|c|c|c|c|c|c|}
\hline & $\begin{array}{c}\text { N. } \\
\text { España }\end{array}$ & $\begin{array}{c}\text { Media } \\
\text { España }\end{array}$ & $\begin{array}{c}\text { Desviación } \\
\text { estándar España }\end{array}$ & $\begin{array}{c}\text { N. } \\
\text { Inglaterra }\end{array}$ & $\begin{array}{c}\text { Media } \\
\text { Inglaterra }\end{array}$ & $\begin{array}{c}\text { Desviación } \\
\text { estándar Inglaterra }\end{array}$ \\
\hline B2.24.1 & 343 & 2,97 & 1,042 & 162 & 3,39 &, 986 \\
\hline B2.24.2 & 343 & 3,78 &, 895 & 162 & 3,63 &, 958 \\
\hline B2.24.3 & 343 & 4,23 &, 815 & 162 & 4,59 &, 596 \\
\hline B2.24.4 & 343 & 4,07 &, 871 & 162 & 3,86 &, 962 \\
\hline B2.24.5 & 343 & 3,90 &, 915 & 162 & 3,62 &, 892 \\
\hline B2.24.6 & 343 & 3,70 &, 952 & 162 & 3,53 &, 879 \\
\hline B2.24.7 & $\mathbf{3 4 3}$ & $\mathbf{4 , 3 1}$ & $\mathbf{, 8 2 2}$ & $\mathbf{1 6 2}$ & $\mathbf{4 , 2 3}$ &, $\mathbf{7 3 3}$ \\
\hline B2.24.8 & 343 & 3,96 &, 894 & 162 & 3,42 & 1,014 \\
\hline B2.24.9 & 343 & 4,01 &, 836 & 162 & 3,91 &, 810 \\
\hline B2.24.10 & 343 & 3,28 & 1,100 & 162 & 3,11 & 1,028 \\
\hline B2.24.11 & 343 & 3,36 &, 935 & 162 & 3,47 &, 934 \\
\hline B2.24.12 & 343 & 3,17 & 1,101 & 162 & 1,93 & 1,016 \\
\hline B2.24.13 & 343 & 3,17 & 1,109 & 162 & 2,18 & 1,034 \\
\hline B2.24.14 & $\mathbf{3 4 3}$ & $\mathbf{3 , 5 2}$ & $\mathbf{1 , 0 6 2}$ & $\mathbf{1 6 2}$ & $\mathbf{3 , 4 2}$ & $\mathbf{1 , 0 3 8}$ \\
\hline
\end{tabular}


En los gráficos 1 y 2 se refleja la valoración que hicieron los docentes en formación de los ítems 2.24.7 y 2.24.14, asociados a los museos y otros centros de interés histórico, y a las fiestas y tradiciones locales de contenido histórico. En ambos se comprueba que las puntuaciones de los estudiantes españoles e ingleses fueron muy parecidas. Sin embargo, se aprecia que los participantes de universidades españolas le otorgaron un porcentaje mayor de respuestas a la puntuación más alta (5) en ambos ítems. Un aspecto que se comprueba con claridad en el Gráfico 1, sobre los museos. Casi el 50\% de los docentes en formación encuestados le dieron la máxima puntuación. Sin duda el incremento de estudios sobre educación patrimonial en España y sus vínculos con la educación histórica es una de las causas de esta gran estimación. La estrecha relación entre historia, memoria y conciencia histórica (Gosselin \& Livingston, 2016) contribuye a que el patrimonio sea tan importante en la clase de Historia, y los docentes en formación así lo perciben, a pesar de que en otros estudios hemos comprobado que en los recuerdos que tienen de la clase de Historia en Educación Secundaria, el patrimonio no ocupaba un lugar principal como recurso, ya que la utilización que se hace del patrimonio cultural como recurso educativo, al menos en la Región de Murcia, es insuficiente. Incluso el profesorado en activo considera dichas visitas como un instrumento secundario o complementario (Gómez, Rodríguez \& Mirete, 2016; Monteagudo, Miralles \& Martínez, 2009).

Gráfico 1. Valoración del ítem "Museos y otros centros de interés histórico" como recurso de enseñanza de la historia (en porcentaje)

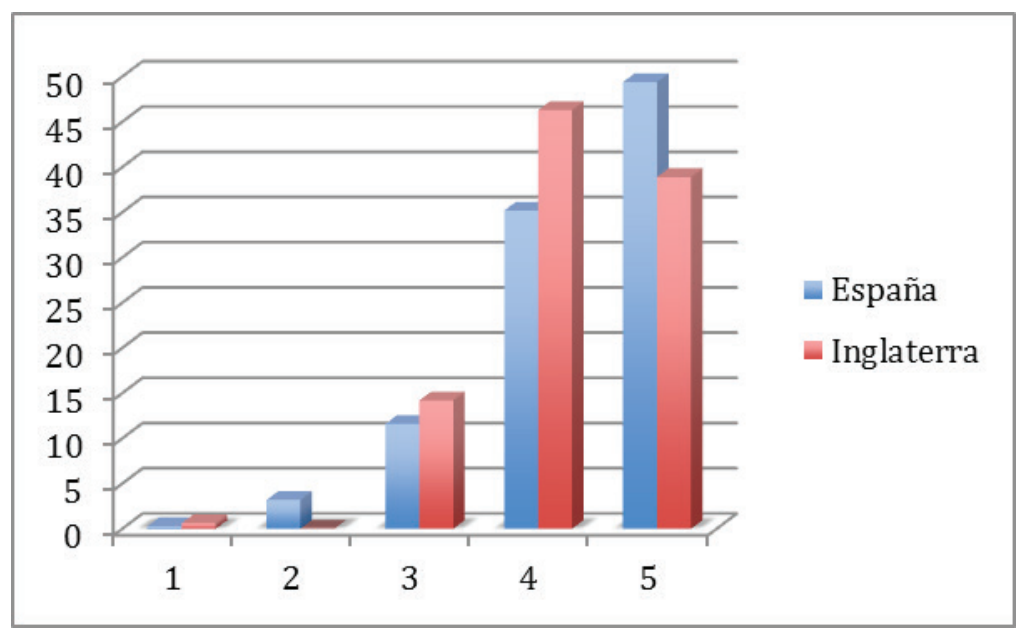


Gráfico 2. Valoración del ítem "Fiestas y tradiciones locales de contenido histórico" como recurso de enseñanza de la historia (en porcentaje)

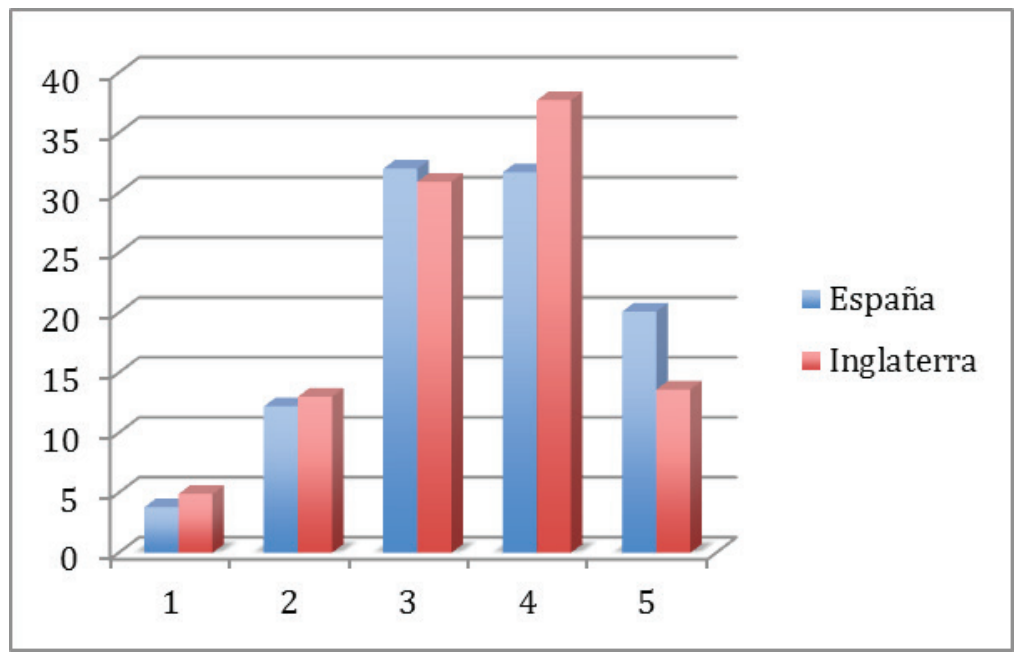

Otro de los focos del cuestionario fue comprobar la percepción de los estudiantes sobre las estrategias metodológicas (bloque 2.25 del cuestionario). En la Tabla 10 están reflejados los estadísticos descriptivos sobre este bloque de ítems, en el que se pedía que los estudiantes valoraran los métodos y las estrategias más adecuados para la enseñanza de la historia en Educación Secundaria. Como se comprueba en la tabla, el ítem "Salidas a centros de interés histórico del entorno cercano" obtiene una valoración superior a 4 en ambos países. Sin embargo, y al contrario que en el caso anterior, no obtiene una puntuación tan alta como otros ítems. La diferencia entre ambos países es un poco más acusada, como se puede ver en el Gráfico 3. Los docentes en formación españoles siguen dándole una estimación muy alta (casi el 50\% le otorga una puntuación de 5), mientras que los estudiantes ingleses optan mayoritariamente por el 4 de puntuación. En el caso inglés solamente la explicación del profesor y las estrategias de simulación histórica quedan por debajo en puntuación. En el caso español, además de estas dos, los debates sobre temas históricos también quedan valorados por debajo. Mientras que en España el ítem más valorado es utilizar temas clave de interés actual para conectar pasado y presente, en Inglaterra el ítem más valorado sobre las estrategias metodológicas es la resolución de problemas de tipo histórico a través de la búsqueda, selección y tratamiento de la información. 
Estudios Pedagógicos XLIII, N 4: 161-184, 2017

PATRIMONIO, COMPETENCIAS HISTÓRICAS Y METODOLOGÍAS ACTIVAS DE APRENDIZAJE. UN ANÁLISIS DE LAS OPINIONES DE LOS DOCENTES EN FORMACIÓN EN ESPAÑA E INGLATERRA

Tabla 10. Estadísticos descriptivos del bloque 2.25 del cuestionario

\begin{tabular}{|c|c|c|c|c|c|c|}
\hline & $\begin{array}{c}\text { N. } \\
\text { España }\end{array}$ & $\begin{array}{c}\text { Media } \\
\text { España }\end{array}$ & $\begin{array}{c}\text { Desviación } \\
\text { estándar España }\end{array}$ & $\begin{array}{c}\text { N. } \\
\text { Inglaterra }\end{array}$ & $\begin{array}{c}\text { Media } \\
\text { Inglaterra }\end{array}$ & $\begin{array}{c}\text { Desviación } \\
\text { típica Inglaterra }\end{array}$ \\
\hline B2.25.1 & 341 & 4,04 &, 822 & 162 & 3,96 &, 990 \\
\hline B2.25.2 & 341 & 3,89 &, 895 & 162 & 3,62 & 1,004 \\
\hline B2.25.3 & 341 & 4,60 &, 632 & 162 & 4,23 &, 907 \\
\hline B2.25.4 & 341 & 4,34 &, 732 & 162 & 4,48 &, 642 \\
\hline B2.25.5 & 341 & 4,30 &, 746 & 162 & 4,34 &, 749 \\
\hline B2.25.6 & $\mathbf{3 4 1}$ & $\mathbf{4 , 2 8}$ & $\mathbf{, 7 9 8}$ & $\mathbf{1 6 2}$ & $\mathbf{4 , 0 9}$ & $\mathbf{8 5 9}$ \\
\hline B2.25.7 & 341 & 4,14 &, 856 & 162 & 4,25 &, 734 \\
\hline
\end{tabular}

Gráfico 3. Valoración del ítem "Salidas a centros de interés histórico del ámbito cercano" como método de enseñanza de la historia (en porcentaje)

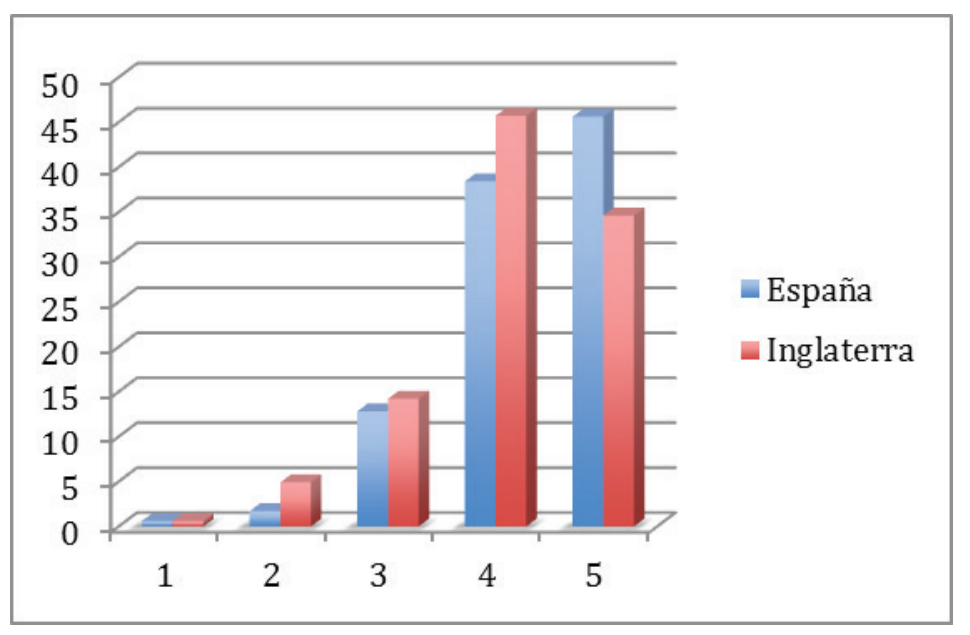

Además de las estrategias y los recursos en la clase de Historia, en el cuestionario se pidió a los estudiantes la valoración sobre procedimientos, actividades e instrumentos de evaluación. En la Tabla 11 se muestran los ítems que debían valorar los docentes en formación sobre la adecuación de esos ejercicios y actividades para evaluar el aprendizaje de los contenidos y las competencias históricas en Educación Secundaria. Los ítems asociados al patrimonio: "Trabajo de campo (recogida de información, realización de ejercicios) a lo largo de una visita a un museo u otro centro de interés histórico" e "Investigaciones de historia local" reciben una puntuación alta en el caso de los estudiantes españoles, y una puntuación más baja en el caso de los estudiantes ingleses, como también se puede comprobar en los gráficos 4 y 5 . Bastante significativo es el ítem de trabajo de 
campo, que recibe una puntuación de 4,22 en los participantes de las universidades españolas y solo un 3,45 en los participantes de universidades inglesas. La mitad de los docentes en formación ingleses lo puntúan con un 2 o un 3, mientras que el $45 \%$ de los españoles lo valoran con la máxima puntuación. Estos datos muestran unas diferentes percepciones sobre el proceso evaluador y las actividades adecuadas para valorar los aprendizajes de la historia en ambas realidades territoriales, como se ha comprobado en otros estudios (Gómez, Miralles \& Chapman, 2017).

Tabla 11. Estadísticos descriptivos del bloque 3.35 del cuestionario

\begin{tabular}{|l|c|c|c|c|c|c|}
\hline & $\begin{array}{c}\mathrm{N} \\
\text { España }\end{array}$ & $\begin{array}{c}\text { Media } \\
\text { España }\end{array}$ & $\begin{array}{c}\text { Desviación } \\
\text { estándar España }\end{array}$ & $\begin{array}{c}\mathrm{N} \\
\text { Inglaterra }\end{array}$ & $\begin{array}{c}\text { Media } \\
\text { Inglaterra }\end{array}$ & $\begin{array}{c}\text { Desviación } \\
\text { estándar Inglaterra }\end{array}$ \\
\hline B3.35.1 & 340 & 4,30 &, 768 & 161 & 4,18 &, 660 \\
\hline B3.35.2 & 340 & 3,15 &, 991 & 161 & 3,49 &, 881 \\
\hline B3.35.3 & 340 & 3,80 &, 892 & 161 & 3,93 &, 965 \\
\hline B3.35.4 & $\mathbf{3 4 0}$ & $\mathbf{4 , 2 2}$ & $\mathbf{, 8 7 6}$ & $\mathbf{1 6 1}$ & $\mathbf{3 , 4 5}$ & $\mathbf{9 4 8}$ \\
\hline B3.35.5 & 340 & 3,90 &, 965 & 161 & 3,29 &, 966 \\
\hline B3.35.6 & $\mathbf{3 4 0}$ & $\mathbf{4 , 0 5}$ & $\mathbf{, 9 3 3}$ & $\mathbf{1 6 1}$ & $\mathbf{3 , 7 1}$ & $\mathbf{, 8 3 2}$ \\
\hline B3.35.7 & 340 & 4,27 &, 759 & 161 & 4,29 &, 728 \\
\hline B3.35.8 & 340 & 2,71 & 1,212 & 161 & 2,99 & 1,267 \\
\hline N válido & 340 & & & 161 & & \\
\hline
\end{tabular}

Gráfico 4. Valoración del ítem "Trabajo de campo (recogida de información, realización de ejercicios) a lo largo de una visita a un museo u otro centro de interés histórico" como ejercicio de evaluación

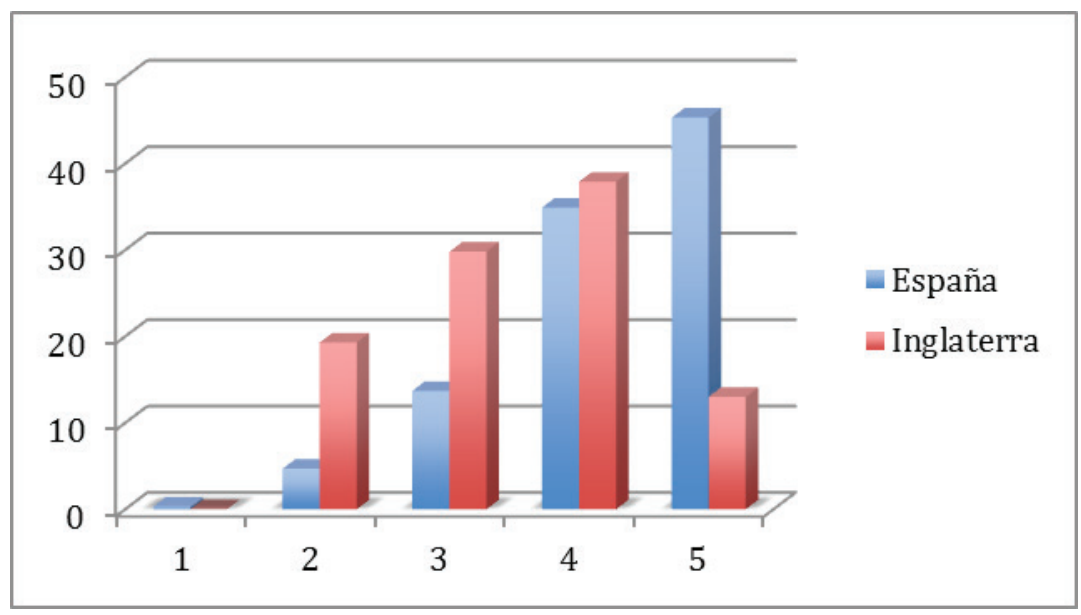


Gráfico 5. Valoración del ítem "Investigaciones de historia local" como ejercicio de evaluación

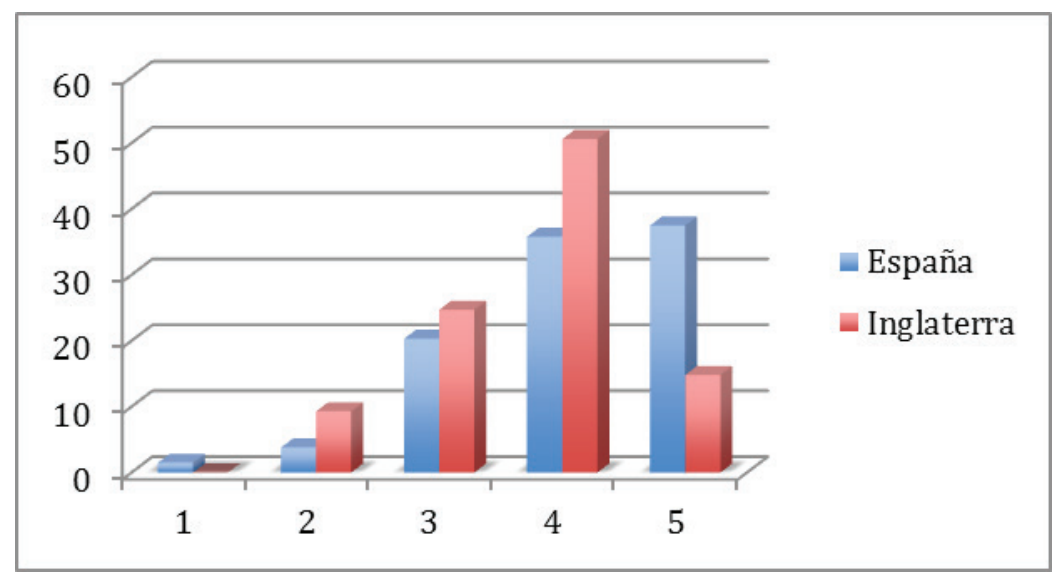

\subsection{VÍNCULOS ENTRE PATRIMONIO, COMPETENCIAS HISTÓRICAS Y METODOLOGÍAS ACTIVAS DE APRENDIZAJE}

Las pruebas estadísticas (Chi-cuadrado y correlaciones de Pearson) nos permiten establecer vínculos entre las respuestas que los docentes en formación dieron sobre los ítems relacionados con el patrimonio, y los que versaban sobre metodologías activas de aprendizaje y el desarrollo y evaluación de competencias históricas. En la Tabla 12 se muestra la prueba del Chi-cuadrado entre el ítem del uso de museos y otros centros de interés histórico como recurso de enseñanza (2.24.7), y el ítem sobre metodología, en el que los docentes en formación debían valorar la adecuación de los estudios en profundidad de casos históricos (2.25.5). El valor del Chi-cuadrado (57,463) y la Sig. Asintótica de ,000 nos indican que hay una relación estadísticamente significativa entre ambos ítems, y por tanto muestran correlación entre ambos. En la Tabla 13 se han reflejado las correlaciones de Pearson entre ese ítem relacionado con el uso de museos como recurso (2.24.7) y diferentes estrategias metodológicas como los estudios en profundidad de casos históricos (2.25.5), utilizar temas claves de interés actual para conectar pasado y presente (2.25.3), y la resolución de problemas de tipo histórico a través de la búsqueda, selección y tratamiento de la información (2.25.4). Esas correlaciones, que son moderadas $(, 242 ;, 251 ;, 327)$, muestran la vinculación estadística entre la percepción del uso del patrimonio en el aula y la necesidad de un cambio metodológico que implique una mayor actividad del alumnado en su proceso de aprendizaje. 
Tabla 12. Prueba del Chi-cuadrado con el ítem 2.24 .7 y 2.25 .5

\begin{tabular}{|l|c|c|c|}
\hline & Valor & gl & Sig. asintótica (2 caras) \\
\hline Chi-cuadrado de Pearson & $57,463^{\mathrm{a}}$ & 16 &, 000 \\
\hline Razón de verosimilitud & 49,329 & 16 &, 000 \\
\hline Asociación lineal por lineal & 36,353 & 1 &, 000 \\
\hline N de casos válidos & 341 & & \\
\hline
\end{tabular}

Tabla 13. Correlación de Pearson entre los ítems 2.24.7, 2.25.3, 2.25.4 y 2.25.5

\begin{tabular}{|l|l|c|c|c|c|}
\hline \multirow{2}{*}{ B2.24.7 } & Correlación de Pearson & 1 &, $242^{* *}$ &, $251^{* *}$ &, $327^{* *}$ \\
\cline { 2 - 6 } & Sig. (bilateral) & &, 000 &, 000 &, 000 \\
\cline { 2 - 6 } & $\mathrm{N}$ & 343 & 341 & 341 & 341 \\
\hline \multirow{3}{*}{ B2.25.3 } & Correlación de Pearson &, $242^{* *}$ & 1 &, $408^{* *}$ &, $334^{* *}$ \\
\cline { 2 - 6 } & Sig. (bilateral) &, 000 & &, 000 &, 000 \\
\cline { 2 - 6 } & $\mathrm{N}$ & 341 & 341 & 341 & 341 \\
\hline \multirow{3}{*}{ B2.25.4 } & Correlación de Pearson &, $251^{* *}$ &, $408^{* *}$ & 1 &, $485^{* *}$ \\
\cline { 2 - 6 } & Sig. (bilateral) &, 000 &, 000 & &, 000 \\
\cline { 2 - 6 } & $\mathrm{N}$ & 341 & 341 & 341 & 341 \\
\hline \multirow{2}{*}{ B2.25.5 } & Correlación de Pearson &, $327^{* *}$ &, $334^{* *}$ &, $485^{* *}$ & 1 \\
\cline { 2 - 6 } & Sig. (bilateral) &, 000 &, 000 &, 000 & 341 \\
\cline { 2 - 6 } & $\mathrm{N}$ & 341 & 341 & 341 & \\
\hline \multirow{2}{*}{$* *$ La correlación es significativa en el nivel $0,01(2$ colas). } & & \\
\hline
\end{tabular}

En cuanto a las correlaciones de los ítems relacionados con el patrimonio y los relacionados con el desarrollo y la evaluación de competencias históricas, en la Tabla 14 se muestra la prueba del Chi-cuadrado entre el ítem del uso de museos y otros centros de interés histórico como recurso en la clase de Historia (2.24.7) y el ítem que afirma que los métodos del historiador y los contenidos procedimentales deben tener un papel fundamental en los currículos educativos (2.18). El valor del Chi-cuadrado $(49,931)$ y la Sig. Asintótica ,000 muestran que ambos ítems tienen una relación estadísticamente significativa. En la Tabla 15, se encuentran las correlaciones de Pearson entre los anteriores ítems (2.24.7 y 2.18) y el ítem en el que los docentes en formación debían valorar la afirmación "Conocer lo métodos de reconstrucción y explicación de los hechos históricos" como una de las finalidades de la enseñanza de la historia. El valor de estas correlaciones, aunque de baja a moderada $(, 252$ y ,215), muestra la vinculación estadística entre la percepción del uso del patrimonio y el desarrollo de competencias históricas a través del método del historiador, el uso de fuentes, etc. 
Estudios Pedagógicos XLIII, N 4: 161-184, 2017

PATRIMONIO, COMPETENCIAS HISTÓRICAS Y METODOLOGÍAS ACTIVAS DE APRENDIZAJE. UN ANÁLISIS DE LAS OPINIONES DE LOS DOCENTES EN FORMACIÓN EN ESPAÑA E INGLATERRA

Tabla 14. Prueba del Chi-cuadrado entre el ítem 2.24 .7 y 2.18

\begin{tabular}{|l|c|c|c|}
\hline & Valor & gl & Sig. asintótica (2 caras) \\
\hline Chi-cuadrado de Pearson & $49,931^{\text {a }}$ & 16 &, 000 \\
\hline Razón de verosimilitud & 51,681 & 16 &, 000 \\
\hline Asociación lineal por lineal & 15,828 & 1 &, 000 \\
\hline N de casos válidos & 343 & & \\
\hline
\end{tabular}

Tabla 15. Correlaciones de Pearson entre los ítems 2.24.7, 2.23.4 y 2.18

\begin{tabular}{|c|c|c|c|c|}
\hline & & B2.24.7 & B2.23.4 & B2.18 \\
\hline \multirow{3}{*}{ B2.24.7 } & Correlación de Pearson & 1 &, $252^{* *}$ & $215^{* *}$ \\
\hline & Sig. (bilateral) & &, 000 &, 000 \\
\hline & $\mathrm{N}$ & 343 & 343 & 343 \\
\hline \multirow{3}{*}{ B2.23.4 } & Correlación de Pearson &, $252^{* *}$ & 1 & $252^{* *}$ \\
\hline & Sig. (bilateral) & 000 & & 000 \\
\hline & $\mathrm{N}$ & 343 & 343 & 343 \\
\hline \multirow{3}{*}{ B2.18 } & Correlación de Pearson &, $215^{* *}$ &, $252^{* *}$ & 1 \\
\hline & Sig. (bilateral) &, 000 &, 000 & \\
\hline & $\mathrm{N}$ & 343 & 343 & 343 \\
\hline
\end{tabular}

\section{CONCLUSIONES}

Los dos primeros objetivos de este trabajo se han centrado en comparar la valoración que tienen los docentes en formación de España e Inglaterra sobre el patrimonio y su papel en el proceso de enseñanza aprendizaje de la historia y en la evaluación de competencias históricas. Los datos del cuestionario respondido por docentes en formación de Educación Secundaria de ambos países son interesantes para llevar a cabo un análisis comparativo entre dos países con modelos educativos distintos. El punto de partida común de las respuestas analizadas es una valoración positiva de las metodologías activas de aprendizaje, así como el trabajo con fuentes y el desarrollo de competencias históricas. Esta valoración tan positiva es resultado del esfuerzo llevado a cabo en las últimas décadas por grupos de investigación e innovación en educación histórica a nivel internacional, que han abogado por superar las metodologías docentes basadas en contenidos lineales y factuales, a favor de una enseñanza de la historia crítica y que aporte valores cívicos. Los docentes tanto españoles como ingleses coinciden en que la historia forjadora de élites y patriotas no sirve en el contexto multicultural y global, algo que concuerda con las investigaciones llevadas a cabo en los últimos años. Así pues, frente a memorización acrítica del pasado (Lévesque \& Zanazanian, 2015), los futuros docentes apuestan por recursos, estrategias metodológicas, 
y procedimientos de evaluación que desarrollen el pensamiento histórico en el alumnado, mediante el uso de fuentes históricas y el razonamiento crítico. Es el método del historiador, la capacidad de interrogar a una fuente histórica, contextualizarla y buscar respuestas la clave de la historia como disciplina (Prats, 2016). El uso del patrimonio para trabajar las fuentes y pruebas históricas es una de las principales líneas de investigación en educación patrimonial (Pinto, 2013). Con ello se permite a los estudiantes expresar cómo comprenden el pasado a partir de las inferencias que realizan partiendo de fuentes y tomando conciencia de su orientación del tiempo histórico. Este trabajo con fuentes abre las puertas a nuevas formas de abordar el uso de material patrimonial desde el ámbito educativo, para contribuir al desarrollo de la conciencia histórica y la equidad, centrándose en actividades de aula (Miralles \& Alfageme, 2013).

Por tanto, el patrimonio puede jugar un papel decisivo en ese sentido, y así es percibido en los docentes de formación de España e Inglaterra, a tenor de las respuestas obtenidas en el cuestionario, aunque con algunos matices. Los futuros docentes españoles otorgan una puntuación alta o muy alta al patrimonio como recurso didáctico en el aula de historia y como estrategia metodológica o técnica de evaluación. En el caso inglés los datos muestran unas respuestas más moderadas. Los estudiantes ingleses, a pesar de puntuar entre moderado y alto al patrimonio como recurso, le dan más importancia a las fuentes primarias, a la resolución de problemas de tipo histórico mediante la búsqueda y selección de fuentes y pruebas históricas, o ejercicios de evaluación centrados en la explicación causal o la argumentación histórica. No nos puede extrañar que los docentes ingleses encuestados den mayor relevancia al uso de fuentes primarias para la enseñanza de la historia que los españoles. Esto alude a tradiciones docentes diferenciadas, con una visión más metodológica y procedimental de la historia en Inglaterra, donde el impacto de proyectos de investigación como el CHATA o los cambios introducidos por el National Curriculum de 1991 son más que evidentes. Pero es curioso que no vinculen de forma más estrecha estas cuestiones a la potencialidad que tiene el patrimonio para llevarlas a cabo, como sí ocurre en el caso español. Por un lado, la gran vitalidad bibliográfica de la educación patrimonial en España tiene parte de responsabilidad en esta valoración (Fontal \& Ibáñez, 2017). También el peso importante que tiene la historia del arte dentro del currículo y los libros de texto españoles frente a las propuestas inglesas (Gómez y Chapman, 2017). Ahora bien, en ambos países la visión de la historia local y el patrimonio inmaterial sigue teniendo una valoración más modesta.

El tercer y último objetivo ha consistido en analizar las correlaciones entre los ítems del cuestionario para interpretar las diferentes formas de concebir el patrimonio en la clase de Historia y en la evaluación de competencias históricas por parte de los docentes en formación de España e Inglaterra. Los resultados muestran que existen correlaciones estadísticas significativas (dependiendo de los casos de bajas a moderadas o moderadas) entre las respuestas que los docentes en formación otorgaron a los ítems sobre el patrimonio como recurso y ejercicio de evaluación, y las percepciones que tienen sobre las metodologías activas de aprendizaje y sobre la historia como materia formativa. El patrimonio (museos y otros centros históricos) es visto por los docentes en formación de ambos países como un recurso importante para la enseñanza de la historia. Pero los futuros docentes lo vinculan por un lado como un potente recurso que permite el desarrollo de metodologías activas de aprendizaje donde el alumnado va construyendo su conocimiento. Y por otro lado como una fuente histórica de gran valor que permite al alumnado introducirse en el método del 
historiador y aprender a plantear interrogantes históricos. El uso de fuentes primarias, el desarrollo del pensamiento histórico y de los procedimientos del historiador ayudan a que al alumnado desarrolle competencias para el análisis social. Por un lado, familiarizando al alumnado con el método histórico, con el método del historiador. Por otro, incrementando la capacidad crítica que genera este conocimiento, lo que converge con las propuestas de Rüsen (2015), y se integra en la tradición historiográfica que proviene de la definición de conciencia histórica. Una tradición historiográfica donde también juega un papel importante el vínculo entre el patrimonio material e inmaterial y la construcción de identidades colectivas.

\section{IMPLICACIONES EDUCATIVAS}

Es preciso llevar a las aulas procedimientos que impliquen una correcta didáctica del patrimonio. En primer lugar se encuentran las propuestas normativas referidas a las leyes educativas y los currículos, que deben ampliar la presencia del patrimonio en los textos y las normas legales. Además, es clave la concepción que otorgue el currículo al patrimonio, en la medida en que puede favorecer o dificultar la introducción del mismo en la enseñanza, pues orienta la elaboración de materiales, el proyecto curricular de centro, los contenidos de los libros de texto e influye en la formación del profesorado (González \& Pagès, 2003).

El siguiente ámbito de concreción es el centro educativo, que tiene que incluir en el proyecto educativo y las programaciones didácticas el tratamiento del patrimonio a través de programas de salidas mediante las cuales los estudiantes se aproximen al pasado histórico de su propia comunidad, conectando con su realidad más cercana. Es aquí donde la información adquiere su sentido, siendo la experiencia el contexto en el que tendría lugar el aprendizaje y donde se desarrollarían actitudes de valoración y conservación de la pluralidad cultural que rodea al alumnado.

En el ámbito del aula, el patrimonio ha de ser una fuente más en la labor del profesorado, que ha de adoptar un papel activo y una perspectiva crítica para hacer posible la conexión entre aula y entorno, relacionando las actividades y salidas fuera del aula con la programación y los métodos activos como el aprendizaje basado en problemas, que haga que el alumnado se implique en la solución de los problemas planteados, ya sean actuales o pasados, mejorando de este modo la motivación y el interés por la asignatura, viéndola más útil y funcional.

Es preciso modificar los actuales planes de estudios universitarios para enfocarlos hacia una formación que capacite para la docencia a los futuros docentes de Secundaria. Una de las facetas más importantes es aprender a utilizar de forma didáctica las fuentes históricas, entre ellas el patrimonio.

Por último, implica también continuar haciendo de la didáctica del patrimonio un campo de investigación emergente y consolidado dentro de la didáctica de la historia. Todo ello dentro de las premisas de la educación histórica, la construcción de una ciudadanía crítica y la educación identitaria. 


\section{REFERENCIAS BIBLIOGRÁFICAS}

Altamira, R. (1997). La enseñanza de la Historia (ed. orig. 1891). Madrid: Akal.

Ashby, R. (2011). Understanding historical evidence. Teaching and learning challenges. In I. Davies (Ed.), Debates in History Teaching (pp. 137-147). London, New York: Routledge.

Bardavio, A., \& González, P. (2003). Objetos en el tiempo: las fuentes materiales en la enseñanza de las ciencias sociales. Barcelona: ICE Universitat de Barcelona.

Buendía, L., Colás, P., \& Hernández, F. (1998). Métodos de investigación en psicopedagogía. Madrid: McGraw-Hill.

Calaf, R. (2010). Un modelo de investigación didáctica del patrimonio. Enseñanza de la Ciencias Sociales, 9, 17-28.

Copeland, T. (2009). Archaeological heritage education: citizenship from the ground up. Treballs d'Arqueologia, 15, 9-20.

Corbishley, M. (2011). Pinning down the past: archaeology, heritage, and education today. Woodbridge, Suffolk, UK, Rochester, NY: Boydell Press.

Cuenca, J. M. (2002). El patrimonio en la didáctica de las ciencias sociales. Análisis de concepciones, dificultades y obstáculos para su integración en la enseñanza obligatoria. Huelva: Universidad de Huelva. Recuperado de http://rabida.uhu.es/dspace/handle/10272/2648

Cuenca, J. M., \& López, I. (2014). La enseñanza del patrimonio en los libros de texto de Ciencias Sociales, Geografía e Historia para ESO. Cultura y Educación, 26(1), 1-43.

Cuenca, J. M., Estepa, J., \& Martín, M. M. (2017). Patrimonio, educación, identidad y ciudadanía. Profesorado y libros de texto en la enseñanza obligatoria. Revista de Educación, 375, 136-159. doi:10.4438/1988-592X-RE-2016-375-338

Cuenca, J. M., Martín, M., \& Estepa, J. (2011). Historia y videojuegos. Una propuesta de trabajo para el aula de $1^{\circ}$ de ESO. Íber. Didáctica de las Ciencias Sociales, Geografía e Historia, 69, 64-73.

Cuenca, J. M., Molina, S., \& Martín, M. (2017 en prensa). Identidad, ciudadanía y patrimonio. Análisis comparativo de su tratamiento didáctico en museos de Estados Unidos y España. Arbor. Revista de Ciencia, Pensamiento y Cultura.

Davis, P. (2007). Place exploration: museums, identity, community. In S. Watson (Ed.), Museums and their communities (pp. 53-75). Abingdon and New York: Routledge.

De la Calle, M. (2016). Aprendizaje basado en proyectos (ABP): posibilidades y perspectivas en ciencias sociales. Íber. Didáctica de las Ciencias Sociales, Geografía e Historia, 82, 7-12.

Del Moral, C., \& Sobrino, D. (2016). Aprendizaje Basado en Proyectos (ABP) en ciencias sociales. Íber. Didáctica de las Ciencias Sociales, Geografía e Historia, 82, 4-6.

Domínguez, A., \& López, R. (2015). Patrimonio, entorno y procesos de identificación en la educación primaria. Clío. History and History Teaching, 41. Recuperado de http://clio.rediris.es

Domínguez, A., \& López, R. (2017). Patrimonios en conflictos. Competencias cívicas y formación profesional en educación primaria. Revista de Educación, 375, 86-109.

Domínguez, C. (Coord.). (2004). Didáctica de las Ciencias Sociales. Madrid: Pearson.

Domínguez, J. (2015). Pensamiento histórico y evaluación de competencias. Barcelona: Graó.

Estepa, J. (2013). La educación patrimonial en la escuela y el museo: investigación y experiencias. Huelva: Universidad de Huelva.

Éthier, M., Demers, S., \& Lefrançois, D. (2010). Las investigaciones en didáctica sobre el desarrollo del pensamiento histórico en la enseñanza primaria. Una panorámica de la literatura publicada en francés e inglés desde el año 1990. Enseñanza de las Ciencias Sociales. Revista de Investigación, 9, 61-74.

Feliu, M., \& Hernández, M. (2015). El paisaje en la didáctica de las ciencias sociales. Íber. Didáctica de las Ciencias Sociales, Geografía e Historia, 81, 9-14.

Fontal, O. (2003). La educación patrimonial. Teoría y práctica en el aula, el museo e Internet. Gijón: Trea. 
Estudios Pedagógicos XLIII, N 4: 161-184, 2017

PATRIMONIO, COMPETENCIAS HISTÓRICAS Y METODOLOGÍAS ACTIVAS DE APRENDIZAJE. UN ANÁLISIS DE LAS OPINIONES DE LOS DOCENTES EN FORMACIÓN EN ESPAÑA E INGLATERRA

Fontal, O. (2006). Los contenidos actitudinales en la enseñanza de la historia del arte. Íber. Didáctica de las Ciencias Sociales, Geografía e Historia, 49, 47-56

Fontal, O., \& Gómez-Redondo, C. (2016). Heritage Education and Heritagization Processes: SHEO Methodology for Educational Programs Evaluation. Interchange, 47(1), 65-90.

Fontal, O., \& Ibáñez, A. (2015). Estrategias e instrumentos para la educación patrimonial en España. Educatio Siglo XXI, 33(1), 15-32.

Fontal, O., \& Ibáñez, A. (2017). La investigación en Educación Patrimonial. Evolución y estado actual a través del análisis de indicadores de alto impacto. Revista de Educación, 375(1), 84-214.

Gil, P., \& Ibáñez, A. (2013). Percepción de utilidad y grado de satisfacción del alumnado de formación del profesorado con el Método de Caso. Aula Abierta, 41(3), 79-90.

Gómez, C. J., \& Chapman, A. (2017). Enfoques historiográficos y representaciones sociales en los libros de texto. Un estudio comparativo España-Francia-Inglaterra. Historia y Memoria de la Educación, 6, 319-361.

Gómez, C. J., \& Miralles, P. (2015). ¿Pensar históricamente o memorizar el pasado? La evaluación de los contenidos históricos en la educación obligatoria en España. Revista de Estudios Sociales, 52, 52-68. doi:10.7440/res52.2015.04

Gómez, C. J., \& Rodríguez, R. A. (2014). Aprender a enseñar ciencias sociales con métodos de indagación. Los estudios de caso en la formación del profesorado. REDU: Revista de Docencia Universitaria, 12(2), 307-325.

Gómez, C. J., Miralles, P., \& Chapman, A. (2017). Los procedimientos de evaluación en la clase de Historia. Un estudio comparativo a través de las opiniones de los docentes en formación de España e Inglaterra. Revista Electrónica Interuniversitaria de Formación del Profesorado, 20(2), 45-61.

Gómez, C. J., Ortuño, J., \& Molina, S. (2014). Aprender a pensar históricamente. Retos para la historia en el siglo XXI. Tempo e Argumento, 6(11), 1-25.

Gómez, C. J., Rodríguez, R. A., \& Mirete, A. B. (2016). Relación entre metodología docente y uso de recursos de innovación en la enseñanza de la historia. Un análisis a través de los recuerdos de los maestros en formación. Clío. History and History Teaching, 42. Recuperado de http://clio. rediris.es

González, M., \& Feliu, M. (2015). Educación patrimonial e identidad. El papel de los museos en la generación de cohesión social y de vínculos de pertenencia a una comunidad. Clío. History and History Teaching, 41. Recuperado de http://clio.rediris.es

González, N., \& Pagés, J. (2003). La presencia del patrimonio en los currículos de Historia y Ciencias Sociales de la enseñanza obligatoria. En E. Ballesteros (Coord.), El patrimonio y la Didáctica de las Ciencias Sociales (pp. 123-133). Cuenca: Asociación Universitaria de Profesores de Didáctica de las Ciencias Sociales-Universidad de Castilla-La Mancha.

Gosselin, V., \& Livingstone, P. (2016). (Eds). Museums and the Past. Constructing Historical Counsciousness. Vancouver: UBC Press.

Hernández, F., \& Maquilón, J. J. (2010). Introducción a los diseños de investigación educativa. En S. Nieto (Ed.), Principios, métodos y técnicas esenciales para la investigación educativa (pp. 109-126). Madrid: Dykinson.

Ibáñez, A. (2006). Educación y Patrimonio. El caso de los campos de trabajo en la Comunidad Autónoma del País Vasco. Bilbao: Universidad del País Vasco.

Ibáñez, A., Gillate, I., \& Madariaga, J. M. (2015). Utilización de la historia oral para el aprendizaje de contenidos históricos en Educación Secundaria y su relación con la identidad local, la motivación y el autoconcepto social. Tempo e Argumento, 7(16), 204-229.

Ibáñez, A., Vicent, N., \& Asensio, M. (2012). Aprendizaje informal, patrimonio y dispositivos móviles. Evaluación de una experiencia en educación secundaria. Didáctica de las Ciencias Experimentales y Sociales, 26, 3-18.

Ibáñez, A., Vicent, N., Asensio, M., Cuenca, J. M., \& Fontal, O. (2014). Learning in archaeological 
sites with mobile devices. Munibe, 65, 313-321.

Larouche, M. C. (2016). Using Museums Resources and Mobile Technologies to Develop Teens' Historical Thinking Formative Evaluation of an Innovative Educational Set-Up. In V. Gosselin \& P. Livingstone (Eds.), Museums and the Past. Constructing Historical Counsciousness (pp. 122-141). Vancouver: UBC Press.

Lévesque, S. (2011). Le pensée historique: pour le développement de le litératie critique en histoire. Canadian Issues/Thèmes canadiens, Éte/summer, 13-16.

Lévesque, S., \& Zanazanian, P. (2015). History Is a Verb: “We Learn It Best When We Are Doing It!”: French and English Canadian Prospective Teachers and History. Revista de Estudios Sociales, 52, 32-51.

Levstik, L., Henderson, A. G., \& Schlarb, J. S. (2008). Digging for clues: An archaeological exploration of historical cognition. In L. S. Levstik \& K. C. Barton (Eds.), Researching History Education. Theory, Method, and Context (pp. 393-407). New York: Routledge.

Marín, V. (2016). La mejora de la competencia social y ciudadana del alumnado a través de la evaluación. Íber. Didáctica de las Ciencias Sociales, Geografía e Historia, 82, 27-33.

Martín, M. J., \& Cuenca, J. M. (2011). La enseñanza y el aprendizaje del patrimonio en los museos: la perspectiva de los gestores. Revista de Psicodidáctica, 16(1), 99-122.

Miralles, P., \& Alfageme, M. B. (2013). Educación, identidad y ciudadanía en un mundo globalizado y posmoderno. Educatio Siglo XXI, 31(1), 11-24.

Miralles, P., \& Molina, S. (2011). Cómo incorporar el estudio de un acontecimiento, fenómeno o realidad social a la actividad de la clase. En J. Prats (Coord.), Geografía e Historia. Investigación, innovación y buenas prácticas (pp. 121-136). Graó: Barcelona.

Molina, S., Escribano, A., \& Díaz, J. (Eds.). (2016). Patrimonio, identidad y ciudadanía en la enseñanza de las ciencias sociales. Murcia: Editum.

Monteagudo, J. (2014). Iniciación a los estudios de visitantes en museos. Propuesta de elaboración de un cuestionario estándar. Saarbrücken: Publicia.

Monteagudo, J. \& Miralles, P. (2014). Utilización didáctica del patrimonio mediante salidas escolares. Los niveles Bachillerato-COU en la Región de Murcia. Saarbrücken: Publicia.

Monteagudo J., Miralles, P., \& Martínez N. (2009). La formación ciudadana a través de las salidas didácticas para visitar el patrimonio cultural. Un estudio empírico en la región de Murcia. En R. M. Ávila, B. Borghi \& I. Mattozzi (Eds.), L'educazione alla cittadinanza europea e la formazione degli insegnanti. Un progetto educativo per la” Strategia di Lisbona (pp. 405-412). Bolonia: Pàtron Editore.

Oller, M. (2011). Métodos y estrategias para la enseñanza y el aprendizaje de las Ciencias Sociales. En A. Santisteban \& J. Pagès (Coords.), Didáctica del Conocimiento del Medio Social y Cultural en la Educación Primaria (pp. 163-183). Madrid: Síntesis.

Philips, I. (2011). Highlighting evidence. En I. Davies (Ed.), Debates in History Teaching (pp. 212223). London, New York: Routledge.

Pinto, H. (2013). Usos del patrimonio en la didáctica de la historia: perspectivas de alumnos y profesores portugueses relativas a identidad y conciencia histórica. Educatio Siglo XXI, 31(1), 61-88.

Prats, J. (2005). Estudios de caso único como método para el aprendizaje de los conceptos históricos y sociales. Cuadernos digitales. Recuperado de http://www.quadernsdigitals.net/index.php

Prats, J. (2016). Combates por la historia en educación. Enseñanza de las Ciencias Sociales. Revista de investigación, 15, 145-153.

Prats, J., \& Santacana, J. (2011). ¿Por qué y para qué enseñar historia? En J. Prats (Coord.), Didáctica de la Geografía y la Historia (pp. 13-29). Barcelona: Graó.

Prieto, J. A., Gómez, C. J., \& Miralles, P. (2013). El uso de fuentes primarias en el aula y el desarrollo del pensamiento histórico y social. Una experiencia en Bachillerato. Clio, 39. Recuperado de http://clio.rediris.es 
PATRIMONIO, COMPETENCIAS HISTÓRICAS Y METODOLOGÍAS ACTIVAS DE APRENDIZAJE. UN ANÁLISIS DE LAS OPINIONES DE LOS DOCENTES EN FORMACIÓN EN ESPAÑA E INGLATERRA

Redondo, J. L. (2016). Diseña tu parque temático. Íber. Didáctica de las Ciencias Sociales, Geografía e Historia, 82, 13-19.

Rivero, P., \& Hernàndez, F. X. (2015). Aprender con y a través del paisaje cultural. Íber. Didáctica de las Ciencias Sociales, Geografía e Historia, 81, 6-8.

Rüsen, J. (2015). Teoria da História. Uma teoria da história como ciencia. Curitiba: Universidade Federal do Paraná.

Sáiz, J. (2013). Alfabetización histórica y competencias básicas en libros de texto de historia y en aprendizaje de los estudiantes. Didáctica de las Ciencias Experimentales y Sociales, 27, 43-66.

Sáiz, J. (2015). Educación histórica y narrativa nacional (Tesis doctoral). Universidad de Valencia.

Sánchez Agustí, M. (2011). Ciudadanía y enseñanza de la historia. Resultados de una intervención en la formación de maestros. Didáctica de las ciencias experimentales y sociales, 25, 3-15.

Santacana, J., \& Llonch, N. (2012). Manual de didáctica del objeto en el museo. Gijón: Trea.

Santacana, J., \& Llonch, N. (2016). El patrimonio cultural e inmaterial y su didáctica. Gijón: Trea.

Santacana, J., \& Martínez, T. (2013). Patrimonio, identidad y educación: una reflexión teórica desde la historia. Educatio Siglo XXI, 31(1), 47-60.

Santacana, J., \& Masriera, C. (2012). Arqueología reconstructiva y el factor didáctico. Gijón: Trea.

Seixas, P., \& Morton, T. (2013). The big six historical thinking concepts. Toronto: Nelson.

Semedo, A. (2015). Representações e identidade em exposições de museus. Clío. History and History Teaching, 41. Recuperado de http://clio.rediris.es/n41/articulos/mono/MonAsemedo2015.pdf

Tarr, R. (2016). A History Teaching Toolbox. Practical Classroom Strategies. London: Russel Tarr.

Van Boxtel, C., Grever, M., \& Klein, S. (2015). Heritage as a Resource for Enhancing and Assessing Historical Thinking: Reflections from the Netherlands. In K. Ercikan \& P. Seixas (Eds.), New Directions in Assessing Historical Thinking (pp. 40-50). New York: Routledge.

VanSledright, B. A. (2014). Assessing Historical Thinking y Understanding. Innovate Designs for New Standards. New York: Routledge.

Vicent, N., Ibáñez, A., \& Asensio, M. (2015). Evaluación de programas de educación patrimonial de base tecnológica. Virtual Archaeology Review, 13(6), 18-25.

Vicent, N., Rivero, P., \& Feliu, M. (2015). Arqueología y técnicas digitales en educación patrimonial. Educatio Siglo XXI, 33, 83-102.

Wineburg, S. (2001). Historical Thinking and Other Unnaturals Acts: Charting the Future of Teaching the Past. Philadelphia: Temple University Press. 